\title{
Predictors of personality in adolescents
}

Received: 07.05.2016; Revised: 28.09.2016; Accepted: 12.10 .2016

See end of the paper for authors' affiliations

\section{C.K. SINGH}

Department of Human Development and Family Studies, Chaudhary Charan Singh Haryana Agricultural University, HISAR (HARYANA) INDIA
ABSTRACT : According to K. Young, 'Personality is a patterned body of habits, traits, attitudes and ideas of an individual, as these are organized externally into roles and statuses, and as they relate internally to motivation, goals and various aspects of selfhood. A proper and adequate environment is very much necessary for a fruitful learning of the child. Especially the home and the school should provide the necessary stimulus for learning experience. Two environments home and school share an influential space in individual's life and there exists a unique combination between the two. This study examines the, home and school environment on the personality of adolescents. The study was conducted in Hisar city of Haryana state where two colleges and two schools were selected. The sample comprised of 160 adolescents ( 80 girls and 80 boys) taken equally from each institution. Adolescents were assessed for their personality by big five inventory developed John and Srivastava, while home and school environment were measure through respective inventories developed by Mishra. The personality traits among adolescents are significantly and positively correlated with positive home environment dimensions of reward and nurturance. The students showed insignificant association with all the aspects of school environment expect permissiveness.

KEY WORDS: Predictors, Personality, Adolescents

- HOW TO CITE THIS PAPER : Gahlawat, Kritika and Singh, C.K. (2016). Predictors of personality in adolescents. Asian J. Home Sci., 11 (2) : 327-330, DOI: 10.15740/HAS/AJHS/11.2/327-330. 